\title{
c-Abl downregulates the slow phase of double-strand break repair
}

\author{
V Meltser ${ }^{1}, M_{\text {Ben-Yehoyada }}{ }^{1,2}$, N Reuven ${ }^{1}$ and Y Shaul ${ }^{*, 1}$
}

c-Abl tyrosine kinase is activated by agents that induce double-strand DNA breaks (DSBs) and interacts with key components of the DNA damage response and of the DSB repair machinery. However, the functional significance of c-Abl in these processes, remained unclear. In this study, we demonstrate, using comet assay and pulsed-field gel electrophoresis, that c-Abl inhibited the repair of DSBs induced by ionizing radiation, particularly during the second and slow phase of DSB repair. Pharmacological inhibition of $\mathrm{c}-\mathrm{Abl}$ and $\mathrm{c}-\mathrm{Abl}$ depletion by siRNA-mediated knockdown resulted in higher DSB rejoining. c-Abl null MEFs exhibited higher DSB rejoining compared with cells reconstituted for $\mathrm{c}$-Abl expression. Abrogation of $\mathrm{c}-\mathrm{Abl}$ kinase activation resulted in higher $\mathrm{H} 2 \mathrm{AX}$ phosphorylation levels and higher numbers of post-irradiation $\gamma \mathrm{H} 2 \mathrm{AX}$ foci, consistent with a role of $\mathrm{C}-\mathrm{Abl}$ in DSB repair regulation. In conjunction with these findings, transient abrogation of $\mathrm{C}$-Abl activity resulted in increased cellular radioresistance. Our findings suggest a novel function for C-Abl in inhibition of the slow phase of DSB repair.

Cell Death and Disease (2010) 1, e20; doi:10.1038/cddis.2009.21; published online 28 January 2010

Subject Category: Cancer

This is an open-access article distributed under the terms of the Creative Commons Attribution License, which permits distribution and reproduction in any medium, provided the original author and source are credited. This license does not permit commercial exploitation without specific permission.

Damage to both DNA strands comprises a major threat to genome integrity and may lead to the formation of chromosomal aberrations. Following a genotoxic insult, mammalian cells immediately activate a robust stress response - the DNA damage response (DDR) - comprising various mechanisms collectively responsible to prevent the proliferation of cells carrying DNA damage. These include arrest of cell cycle progression, immediate activation of DNA repair mechanisms, as well as possible activation of cell death mechanisms at later stages. ${ }^{1}$ Double-strand DNA break (DSB) repair in mammalian cells is carried out mainly by two mechanisms non homologous end joining (NHEJ) and homologous recombination (HR) - and follows a generally robust pattern consisting of a short phase of fast rejoining kinetics $(\sim 2 \mathrm{~h})$, which repairs the majority of the lesions, and a much longer phase of slow rejoining kinetics during which the remainder of the repair takes place. ${ }^{2,3}$

The non-receptor tyrosine kinase, c-Abl, is ubiquitously expressed and has been implicated in various aspects of the $\mathrm{DDR}^{4,5}$ Its enzymatic activity is normally tightly regulated by structural autoinhibition. However, following DNA damage by agents such as $I R$ and the chemotherapeutic drug Cis-platinum, c-Abl activity is greatly elevated. ${ }^{6-8}$ In response to its activation by DNA damage, c-Abl phosphorylates the p73 tumor suppressor protein and leads to the activation of a p73-dependent apoptotic cell death response. ${ }^{9-11}$ In the context of this response, c-Abl also directly phosphorylates and stabilizes the transcription co-activator Yap1 and thus contributes to selective transcriptional co-activation of $\mathrm{p} 73$ proapoptotic target genes. ${ }^{12}$ However, accumulating evidence involving c-Abl in interactions with general DDR regulators as well as with specific components of both the NHEJ and HR repair mechanisms tends to suggest that c-Abl possesses additional functions in the context of the DDR and in particular in the context of DSB repair. In response to DNA damage, c-Abl interacts with and is phosphorylated by ATM, a key activator of the DDR. ${ }^{13,14}$ DNA-PKcs, an essential NHEJ component, interacts with c-Abl in a DNA damage-stimulated association and the two proteins phosphorylate one another in vitro. ${ }^{15}$ Phosphorylation of c-Abl by DNA-PK activates c-Abl and cells deficient in DNA-PK are defective in IR-induced c-AbI activation, whereas phosphorylation of DNA-PK by c-Abl inhibits the ability of DNA-PK to form a complex with DNA. ${ }^{15}$ Rad51, a mediator of strand exchange in recombination processes and in DSB repair by HR, is phosphorylated by $\mathrm{c}-\mathrm{Abl}$ on a specific tyrosine residue in vitro and in cells in response to irradiation, a phosphorylation which inhibits both the binding of Rad51 to DNA as well as its function in strand exchange reactions. ${ }^{16}$ Rad52, another protein involved in $\mathrm{HR}$, is also phosphorylated by c-Abl and this phosphorylation appears to mediate irradiation-induced Rad52 nuclear foci formation. ${ }^{17}$ WRN, a RecQ helicase participating in multiple processes of DNA metabolism, is phosphorylated by c-Abl following DNA damage, leading to its relocalization from the

\footnotetext{
${ }^{1}$ Department of Molecular Genetics, Weizmann Institute of Science, Rehovot 76100, Israel

*Corresponding author: Y Shaul, Department of Molecular Genetics, Weizmann Institute of Science, Herzel 1, Rehovot 76100, Israel. Tel: +972 89342320 ;

Fax: + 9728934 4108; E-mail: yosef.shaul@ weizmann.ac.il

${ }^{2}$ Current address: Gautier Labaratory, Columbia University, New York, NY 10032, USA.

Keywords: c-Abl tyrosine kinase; DNA damage response; DNA repair; DSB rejoining; ionizing radiation

Abbreviations: DSBs, double-strand DNA breaks; DDR, DNA damage response; NHEJ, non-homologous end joining; HR, homologous recombination

Received 01.12.09; accepted 01.12.09; Edited by G Melino
} 
nucleolus to the nucleoplasm and to the inhibition of its exonuclease and helicase activities. ${ }^{18}$ BRCA1, a nuclear phosphoprotein tightly associated with DSB repair and the $\mathrm{DDR}$, interacts constitutively with c-Abl and this association is disrupted upon infliction of DNA damage. ${ }^{19}$

In view of the mounting evidence for an active role of c-Abl in the DDR, we were motivated to explore the functional consequences of $\mathrm{c}-\mathrm{Abl}$ activity in the context of DSB repair. Our results indicate that $\mathrm{c}-\mathrm{Abl}$ kinase acts to downregulate DSB repair, predominantly during the slow repair phase. In light of the scarcity of existing information regarding negative regulation of DSB repair in mammalian cells, our study contributes to the understanding of DNA repair mechanisms and provides new insights into the function of $\mathrm{c}-\mathrm{Abl}$ in the context of the DDR.

\section{Results}

\section{Inhibition of c-Abl kinase activation results in higher} DSB rejoining. Considering the multiple reported interactions of $\mathrm{c}-\mathrm{Abl}$ with proteins involved in DSB repair, we asked whether $\mathrm{c}-\mathrm{Abl}$ kinase activity has a functional role in regulation of DSB repair processes. To address this question, we used a specific inhibitor of $c$-Abl kinase activity, STI-571. Activation of c-Abl by DNA damage and abrogation of this activation by STI-571 pretreatment was verified by assessing the level of c-Abl tyrosine autophosphorylation (Figure 1a), a modification known to be important for $\mathrm{C}$-Abl kinase activation. ${ }^{20,21} \mathrm{An}$ increase in c-Abl autophosphorylation levels following IR could be detected in control but not in STI-571-treated cells. To assess the effect of $\mathrm{c}$-Abl kinase activity on DSB repair following $\gamma$-irradiation, the comet assay, ${ }^{22,23}$ which provides an estimate for the degree of DSB rejoining in individual cells, was used. wt MEFs were incubated in the presence or absence of STI-571, $\gamma$-irradiated, harvested following $24 \mathrm{~h}$ of incubation and subjected to the comet assay (Figure 1b). A twofold decrease in residual DNA fragmentation could be detected in the STI-571-treated cells compared with their non-treated counterparts, implying that DSB rejoining was significantly higher in cells inhibited for c-Abl activity. To establish the c-Abl specificity of this effect, we used c-Abl null mouse embryonic fibroblasts reconstituted for $c-A b l$ expression. ${ }^{9} \mathrm{c}$-Abl expression was verified by WB (Figure 1c, right panel). Higher levels of residual DNA fragmentation $24 \mathrm{~h}$ after IR could be detected in the c-Abl-reconstituted cells compared with the non-reconstituted c-Abl-/- cells (Figure 1c, left panel).

To further assess the effect of c-Abl kinase activity on DSB repair following $\gamma$-irradiation, DSB rejoining was assayed by pulsed field gel electrophoresis (PFGE), ${ }^{24,25}$ which provides an estimate for the degree of DSB rejoining in a cell population. HeLa cells were incubated with or without STI-571, harvested immediately after $\gamma$-irradiation or following $24 \mathrm{~h}$ of incubation, and genomic DNA fragmentation was determined by PFGE (Figure 1d and e). Results are expressed as the ratio between STI-571 untreated and treated cells. Up to a fourfold difference in residual DNA fragmentation could be detected between the STI-571-treated cells and their counterparts.
STI-571 treatment resulted in significantly lower levels of fragmentation, implying that the levels of DSB rejoining were significantly higher in the absence of $c-A b l$ activity. To ascertain once again that these results represent a c-Ablspecific effect on repair, we performed transient shRNAmediated knockdown of c-Abl. Efficient c-Abl knockdown was confirmed by WB (Figure 1f, right panel). Cells were $\gamma$-irradiated and harvested either immediately or after $24 \mathrm{~h}$ of incubation and analyzed by PFGE (Figure 1f, left panel). c-Abl knockdown resulted in a 1.5-fold difference in the levels of DNA fragmentation. This relatively smaller effect, compared with the one obtained with the c-Abl inhibitor, is likely to be due to incomplete reduction of c-Abl by shRNA. Altogether, these results demonstrate that abrogation of $\mathrm{c}-\mathrm{Abl}$ kinase activity in the context of the DDR results in lower levels of post-IR genomic DNA fragmentation, suggesting that c-Abl downregulates the DSB repair process.

Kinetics of c-Abl mediated inhibition of DSB repair. To assess the effect of $c-A b l$ on DSB repair kinetics, $c-A b l-/-$ MEFs and their counterparts reconstituted for c-Abl expression were subjected to the comet assay at several time points after $\gamma$-irradiation. c-Abl-/- cells generally exhibited lower levels of residual DNA fragmentation compared with cells expressing wt c-Abl, with the difference increasing significantly over time (Figure 2a). Cellular DSB repair, as determined by PFGE, is known to proceed in a biphasic manner, with a fast repair component that is active mainly during the first $0.5-2 \mathrm{~h}$ following DNA damage induction and rejoins close to $80 \%$ of the breaks, and a slow repair component that continues for a significantly longer time and rejoins the remaining breaks. ${ }^{2,3}$ To assess the effect of c-Abl-mediated inhibition of DSB repair on this biphasic pattern of repair, PFGE was performed on STI-571-treated HeLa cells at various time points after $\gamma$-irradiation (Figure $2 b$ ). Consistent with biphasic kinetics, the majority of DSB rejoining occurred within the first few hours following DNA damage induction and slowed down thereafter. Importantly, the analysis revealed that inhibition of $\mathrm{c}-\mathrm{Abl}$ kinase activation resulted in lower levels of residual DNA fragmentation at all time points tested, with the difference increasing dramatically as a function of time and being most pronounced $24 \mathrm{~h}$ post-irradiation (Figure $2 \mathrm{~b}$ ). Such time-dependent kinetics, detected both by PFGE and by the comet assay, suggest that $\mathrm{c}-\mathrm{Abl}$ exerts a significant inhibitory effect on the slow phase of DSB repair. To test whether the kinetics of $\mathrm{c}$-Abl kinase activation correlate with this pattern, c-Abl was immunoprecipitated and an in vitro kinase assay was performed using the c-Abl interactor Abi as a substrate (Figure 2c). Using this approach we could detect a relatively slow time-dependent and dose-dependent activation of c-Abl kinase that was highest $24 \mathrm{~h}$ postirradiation. These slow activation kinetics coincide with the pattern of c-Abl-mediated inhibition of DSB rejoining, supporting the notion that c-Abl downregulated slow-phase repair. Altogether these data suggest that following a genotoxic insult c-Abl kinase is gradually activated and acts to inhibit the extent of DSB repair in the cells, particularly during its slow phase. 
a

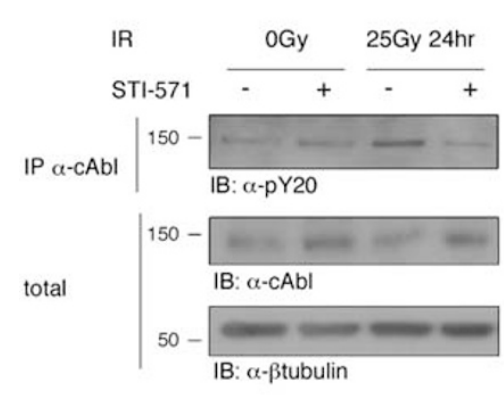

d

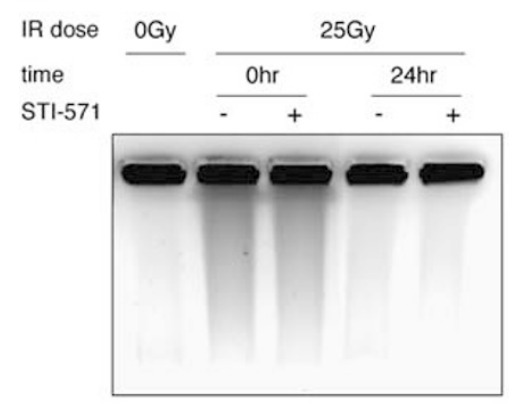

b

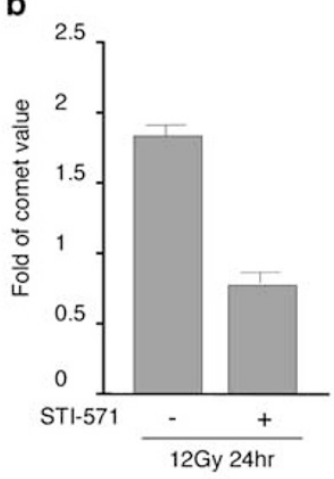

e

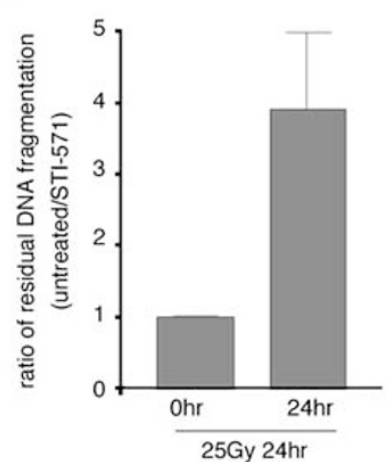

C

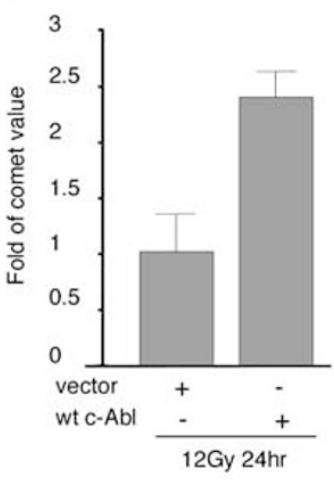

f

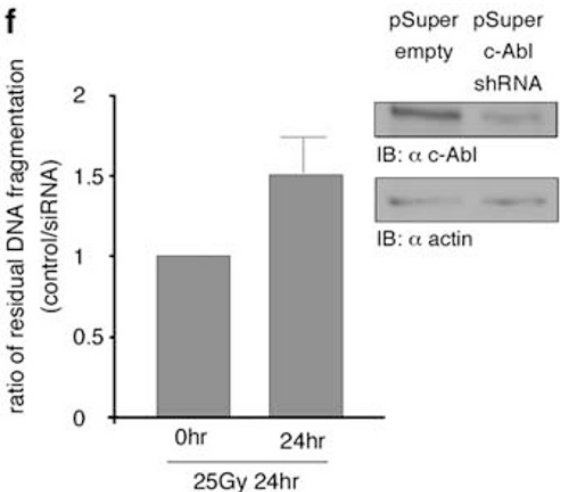

Figure 1 Absence of C-Abl kinase activity results in better DSB rejoining. (a) HeLa cells were pretreated with STI-571 and $\gamma$-irradiated. c-Abl tyrosine autophosphorylation was assayed by immunoprecipitation of endogenous c-Abl, followed by WB for the presence of phosphorylated tyrosine. (b) wt MEFs were pretreated with STI-571, $\gamma$-irradiated and subjected to the comet assay following $24 \mathrm{~h}$ of post-IR incubation at $37^{\circ} \mathrm{C}$. The comet moment value represents the extent of genomic DNA fragmentation in individual cells $(N=50)$. (c) c-Abl-I- MEFs reconstituted for c-Abl expression were $\gamma$-irradiated, harvested after $24 \mathrm{~h}$ of post-IR incubation and subjected to the comet assay. Data are expressed as mean \pm S.D., $N=50$ (left panel). Presence of c-Abl in the reconstituted cells and not in non-reconstituted c-Abl-I-cells was verified by WB (right panel). (d) HeLa cells were pretreated with STI- 571 and $\gamma$-irradiated, cells were collected after $24 \mathrm{~h}$ of incubation at $37^{\circ} \mathrm{C}$ and subjected to PFGE. (e) Same as in (d), the amount of residual DNA fragmentation was quantified and the ratio of fragmentation between untreated and STI-571-treated cells was plotted. Error bars represent S.E.M. for seven independent experiments. The $P$-value for the paired values of STI-571-treated and untreated cells was calculated using Wilcoxon's signed-rank test, $P$-value $<0.001$. (f) HeLa cells were transiently transfected with a pSuper construct carrying shRNA to target c-Abl ${ }^{12}$ or with an empty vector. Following puromycin semiselection, the cells were $\gamma$-irradiated and analyzed by PFGE (left panel). Error bars represent SEM for four independent experiments. The $P$-value for the paired values of knockdown and control cells was calculated using Wilcoxon's signed-rank test, $P$-value $<0.001$. Efficient knockdown of c-Abl was verified by WB (right panel)

Inhibition of c-Abl kinase activation elevates H2AX phosphorylation in response to DNA damage and results in a higher number of $\gamma \mathrm{H} 2 \mathrm{AX}$ foci following DSB repair. To further investigate the function of $\mathrm{c}-\mathrm{Abl}$ in regulation of DSB repair, we tested the formation of IRinduced nuclear foci after pharmacological inhibition of c-Abl activation. Formation of IR-induced foci (IRIF) is a hallmark of the cellular response to DSBs and these foci are likely to represent sites of ongoing DSB repair. ${ }^{26}$ Histone H2AX is a key regulator of IRIF formation. Following DNA damage, it becomes phosphorylated on Ser139 over extensive chromatin regions flanking the DSB, and this modified histone $(\gamma \mathrm{H} 2 \mathrm{AX})$ mediates efficient recruitment and retention of repair factors to the break site. ${ }^{26,27}$ To test whether inhibition of c-Abl kinase activity affects IRIF numbers, post-irradiation $\gamma \mathrm{H} 2 \mathrm{AX}$ levels were examined after STI-571 treatment of HeLa cells. Abrogation of c-Abl kinase activation resulted in higher overall levels of $\gamma \mathrm{H} 2 \mathrm{AX} 4$ and $24 \mathrm{~h}$ after irradiation (Figure $3 \mathrm{a}$ ) and in significantly higher numbers of remaining $\gamma \mathrm{H} 2 \mathrm{AX}$ foci $24 \mathrm{~h}$ after irradiation (Figure $3 b$ and $c$ ). These results are in accordance with an inhibitory role of c-Abl in DSB repair and imply that normally, c-Abl-mediated downregulation of repair leads to a gradual decrease in the numbers of active $\gamma \mathrm{H} 2 \mathrm{AX}$ repair foci, while inhibition of $\mathrm{c}-\mathrm{Abl}$ activity results in foci persistence. The high levels of H2AX phosphorylation in the absence of an active c-Abl kinase may indicate that $\mathrm{c}-\mathrm{Abl}$ normally interferes with the phosphorylation of $\mathrm{H} 2 \mathrm{AX}$ at DSB sites, providing a tentative explanation as to the mechanism by which c-Abl may inhibit DSB repair.

Inhibition of c-Abl kinase activity leads to higher survival rates and higher clonogenic capacity after irradiation. To test the physiological implications of $\mathrm{c}-\mathrm{Abl}$ activity in the context of DSB repair and the DNA damage response, we tested the clonogenic capacity of cells abrogated for c-Abl activity. HeLa cells were pretreated with STI-571 and irradiated with increasing IR doses. For transient inhibition of c-Abl activity, the inhibitor was washed away at post-irradiation times required for completion of either the fast DSB repair phase $(2 \mathrm{~h})$ or of both repair phases $(24 \mathrm{~h})$. The fraction of surviving colonies was determined 14 days after irradiation. Transient abrogation of c-Abl kinase 

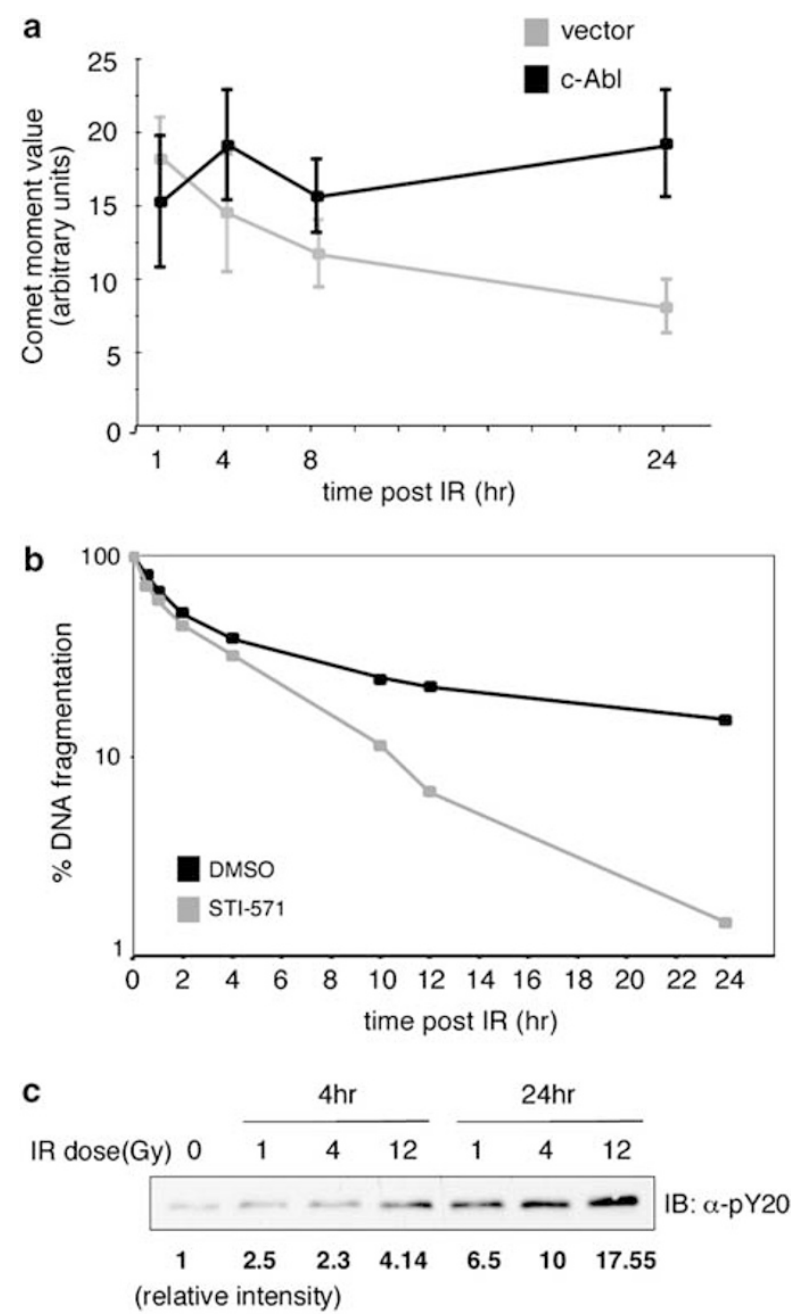

(relative intensity)

IB: $\alpha-\mathrm{cAbl}$

Figure 2 Kinetics of c-Abl-mediated inhibition of DSB repair. (a) c-Abl-IMEFs reconstituted for c-Abl expression were $\gamma$-irradiated (12 Gy), harvested at different time points after post-IR incubation and subjected to the comet assay. Data are expressed as mean \pm S.D., $N=50$. (b) HeLa cells were pretreated with STI$571, \gamma$-irradiated (25Gy), and harvested at different time points after post-IR incubation. Cells were analyzed by PFGE and the percent of residual DNA fragmentation was plotted on a log-scale. (c) c-Abl kinase activity is dose and time dependent. Time and dose kinetics of $\mathrm{c}-\mathrm{Abl}$ kinase activation was determined in MCF7 cells using an in vitro phosphorylation assay. The data were quantified after normalization to c-Abl protein levels

activity resulted in considerably higher clonogenic survival compared with cells harboring active c-Abl (Figure $4 a$ and b). Consistent with a previous report, ${ }^{28}$ these results indicate that abrogation of $\mathrm{c}$-Abl kinase activity confers radioresistance and results in higher post-irradiation clonogenic survival rates. The difference in clonogenic survival after pharmacological inhibition of c-Abl activity was significantly more pronounced when c-Abl activity was abrogated for $24 \mathrm{~h}$ post-irradiation. This time frame correlates with the duration of the slow phase of DSB repair, the one predominantly affected by $\mathrm{c}-\mathrm{Abl}$ regulation, suggesting that $\mathrm{c}-\mathrm{Abl}$-mediated downregulation of DSB repair may confer sensitivity to $\gamma$-irradiation and contribute to post-irradiation cell death. a

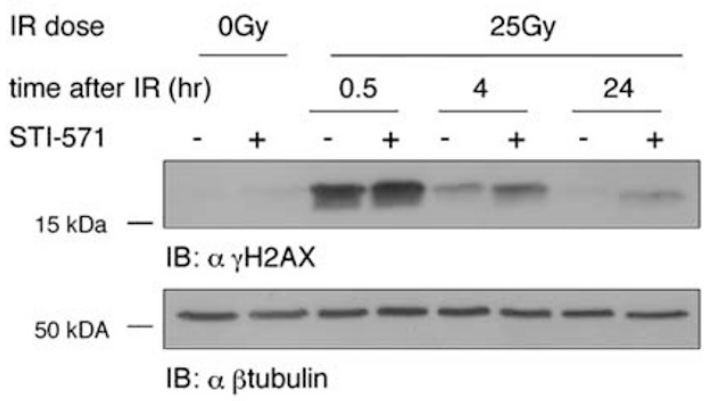

b

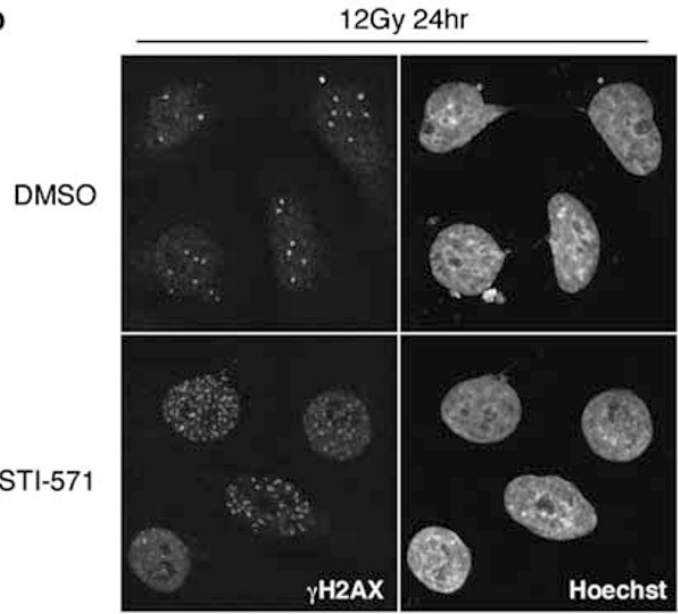

C

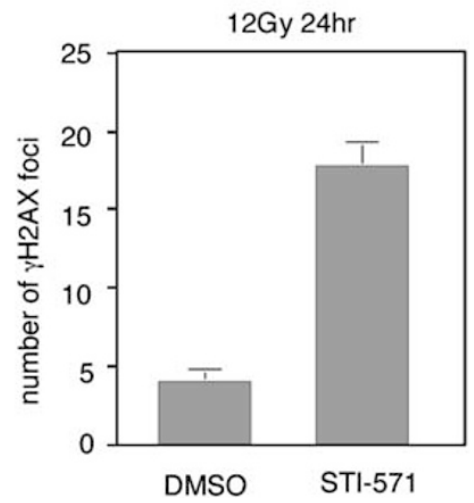

Figure 3 Inhibition of c-Abl kinase activity in the context of the DNA damage response results in persistence of $\mathrm{H} 2 \mathrm{AX}$ phosphorylation. (a) HeLa cells were pretreated with STI-571, $\gamma$-irradiated, and harvested at three time points after irradiation, and the extent of H2AX phosphorylation on Ser139 was assessed by WB. (b, c) Cells were treated as in (a) and subjected to immunofluorescence. For counting purposes, at least 50 nuclei were analyzed per sample. Data are expressed as mean \pm S.E.M.

\section{Discussion}

The cellular defenses against DNA damage ensure an immediate and robust repair response to genotoxic insults. DSB repair proceeds in a biphasic manner, consisting of a short and dominant phase of fast rejoining kinetics $(\sim 2 \mathrm{~h})$ and a much longer phase of slow rejoining kinetics. Correct rejoining occurs primarily during the fast rejoining phase, whereas misrejoining follows much slower kinetics and occurs mainly during the second repair phase..$^{29,30}$ In light of the 
post-IR wash
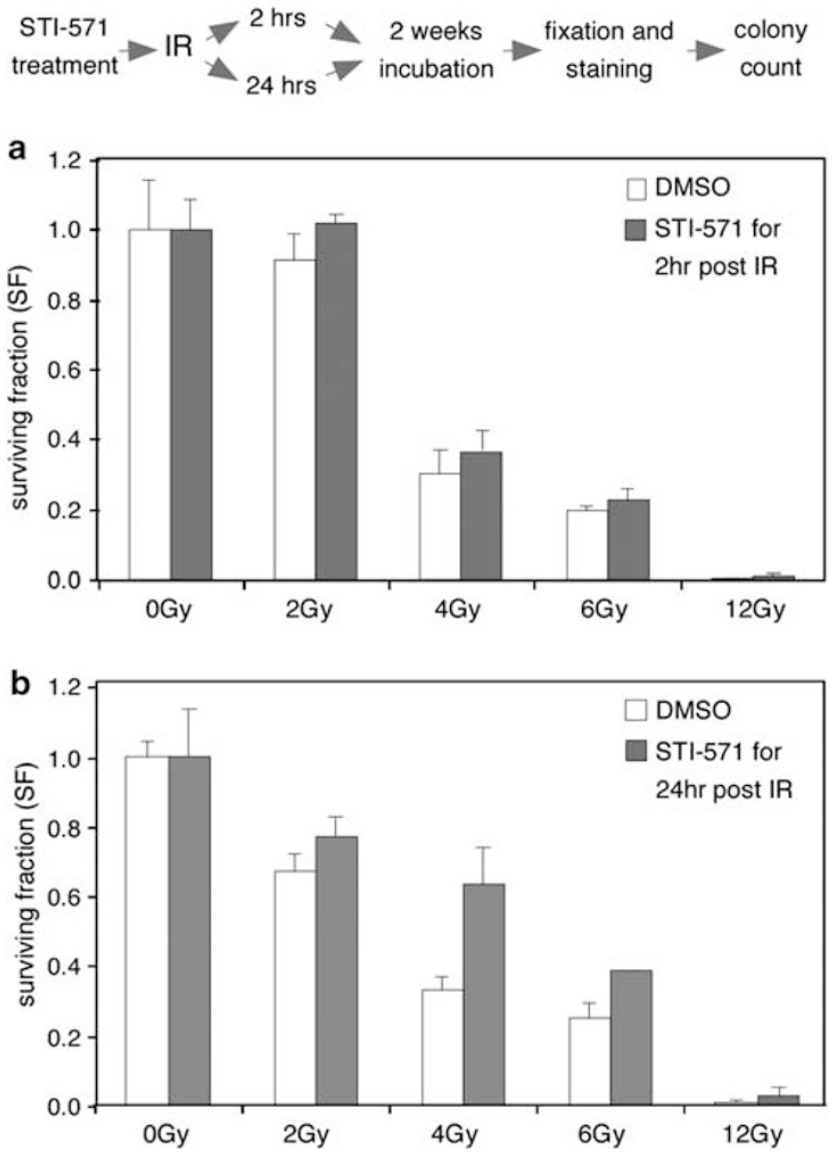

Figure 4 Inhibition of c-Abl kinase activity in the context of the DNA damage response leads to higher post-irradiation clonogenic survival rates. Sparsely seeded cells were pretreated with STI-571 and $\gamma$-irradiated with increasing doses. STI-571 was washed out by medium exchange either $2 \mathrm{~h}(\mathbf{a})$ or $24 \mathrm{~h}(\mathbf{b})$ after IR. The fraction of surviving colonies out of the number of cells seeded was determined by colony count 2 weeks after irradiation. Data are expressed as mean of two experiments \pm S.E.M.

highly undesired outcomes of incorrect DSB repair, the need for mechanisms to regulate the second and error-prone phase is apparent. In this study, we provide evidence for a mechanism for downregulation of slow-phase DSB repair, controlled by the c-Abl tyrosine kinase. Inhibition of c-Abl activity and shRNA-mediated knockdown of c-Abl resulted in markedly elevated DSB rejoining at late repair stages, while reintroduction of $\mathrm{C}-\mathrm{Abl}$ into $\mathrm{C}-\mathrm{Abl}-\mathrm{I}-\mathrm{cells}$ led to decreased rejoining. $\mathrm{c}-\mathrm{Abl}$ post-irradiation activation kinetics correlated well with the predominantly late-phase inhibitory effect of c-Abl on DSB rejoining. Altogether, these observations indicate that normally, DDR-activated $\mathrm{c}$-Abl negatively regulates slow-phase DSB repair progression, consistent with its numerous interactions with DSB repair components such as DNA-PKcs, ${ }^{15}$ Rad51, ${ }^{16}$ Rad52, ${ }^{17}$ BRCA1, ${ }^{19}$ and WRN ${ }^{18}$

How can this function of $\mathrm{c}$-Abl be reconciled with its wellestablished role in the p73-dependent cell death response to DNA damage $?^{4,5,31}$ Downregulation of DSB repair by c-Abl precedes the time frame of post-irradiation cell death and thus may form an early step in the p73-dependent cell death response. In support of such a scenario, abrogation of c-Abl activity, within the time frame of the c-Abl effect on repair, significantly reduces cellular radiosensitivity and increases post-irradiation clonogenic capacity, results which are also in accordance with a finding that STI-571 protects mouse oocytes from chemotherapy-induced death. ${ }^{32}$ Interestingly, p73 itself regulates the transcription of several DSB repair genes following DNA damage ${ }^{33}$ raising the possibility of an interconnection between cell death and DSB repair regulation in the context of p73 and, possibly, in the context of the c-Abl-p73 pathway.

Alternatively, downregulation of DSB repair by c-Abl may occur independently of cell death. In fact, in light of the slowphase predominance of the c-Abl effect on repair, it is tempting to consider it as a mechanism that may prevent incorrect and unfaithful rejoining, thereby promoting the survival of viable cells with an intact and correctly repaired genome. c-Abl, which is activated by irradiation in a dose-dependent manner (Figure 2c), could possibly act as a sensor for the degree of absorbed genotoxic stress and arbitrate accordingly between prevention of incorrect repair in the interests of cell survival and activation of cell death in the event of excessive damage, which cannot be correctly dealt with within the framework of DNA repair.

A well-known example of a protein that coordinates the regulation of both programmed cell death and DNA repair in the context of the DDR is the p53 tumor suppressor. ${ }^{34}$ Independently of its well-known function in transactivation of proapoptotic genes, p53 also regulates various forms of DNA repair, among them NHEJ and $\mathrm{HR}^{34}$ Interestingly, much of the evidence in favor of this p53 function speaks of an inhibitory effect of $\mathrm{p} 53$ on DSB repair. ${ }^{34}$ It has been proposed that p53 could act as a 'molecular node,' integrating signals from various signaling pathways and mediating between the modulation of DNA repair pathways and the transactivation of proapoptotic and cell cycle arrest genes. ${ }^{34}$ In light of this functional analogy between $\mathrm{c}-\mathrm{Abl}$ and $\mathrm{p53}$, it is possible that c-Abl could also act in the form of a molecular switch, mediating cell-fate decisions and inducing a shift from prosurvival to pro-death mechanisms under the appropriate circumstances.

A positive role for $\mathrm{c}-\mathrm{Abl}$ in DNA repair has been argued by Fanta et al., ${ }^{35}$ who show that treatment of hematopoietic cells with STI-571 results in lower DSB rejoining levels after $\gamma$-irradiation. However, the experimental setting used by the authors is fundamentally different and is based on prolonged incubation of the cells with the inhibitor before irradiation. The discrepancy between the results could stem either from cell-type-specific effects or from the prolonged inhibition of c-Abl activation.

According to our model (Figure 5b), c-Abl becomes gradually activated by $\gamma$-irradiation in response to DNA damage to reach a threshold of DSB repair inhibition predominantly during the slow repair phase, when most of the illegitimate repair events take place. ${ }^{29,30}$ The mechanism responsible for this repair downregulation can be at least partially explained by the reported c-Abl-mediated modification and inhibition of several members of the DSB repair machinery. ${ }^{15-19}$ Our finding that $\mathrm{c}-\mathrm{Abl}$ inhibition resulted in higher post-irradiation $\gamma \mathrm{H} 2 \mathrm{AX}$ levels may shed some new light on the mechanism involved. Following c-Abl inhibition, the levels of post-repair DNA fragmentation decreased significantly. We therefore expected to detect lower levels of $\gamma \mathrm{H} 2 \mathrm{AX}$. However, contrary to our expectations higher levels of $\gamma \mathrm{H} 2 \mathrm{AX}$ were detected. Therefore, $\mathrm{C}-\mathrm{Abl}$ appears to downregulate $\gamma \mathrm{H} 2 \mathrm{AX}$ activation and may thereby reduce the 


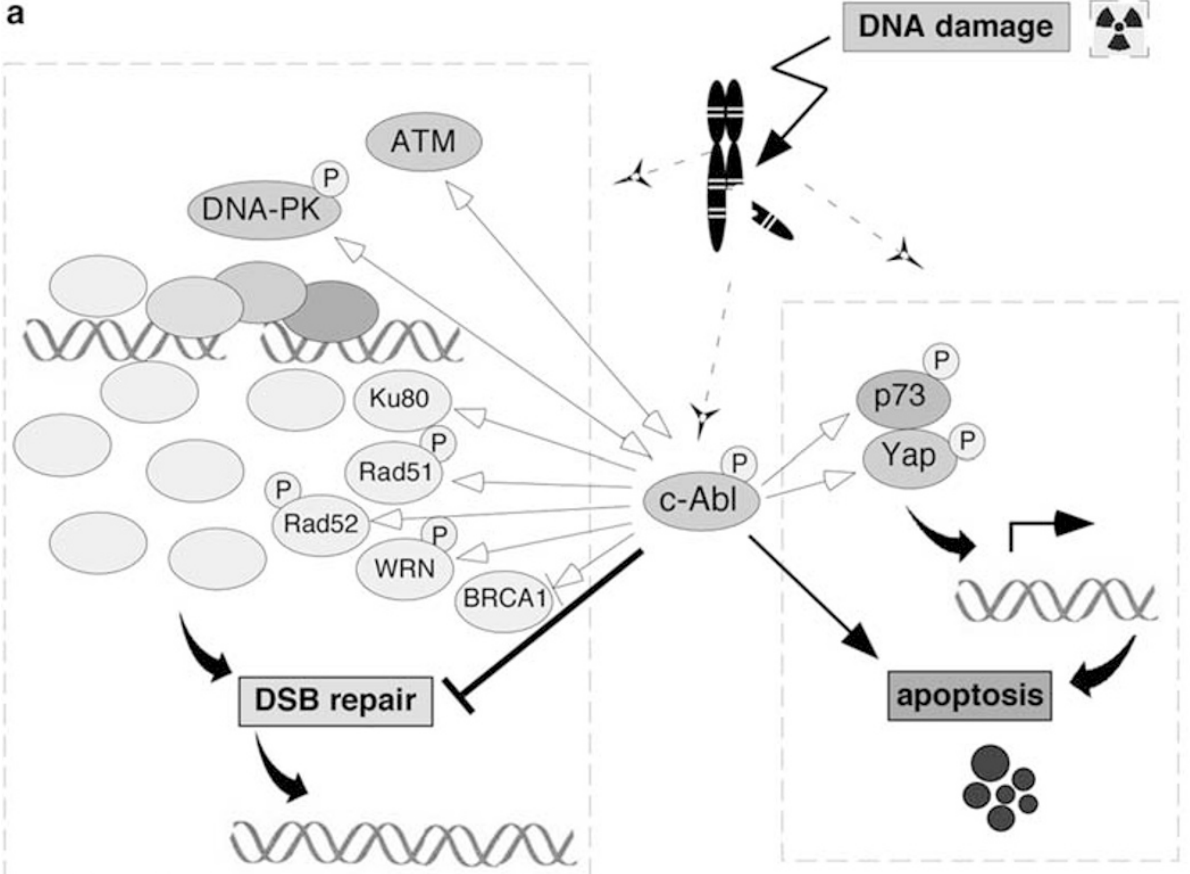

b

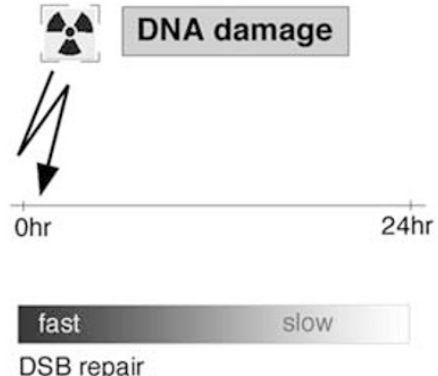

error-prone DSB repair

c-Abl kinase activation

C-Abl mediated down-regulation of DSB repair

Figure 5 General model for the involvement of c-Abl in the DNA damage response and in regulation of DSB repair. (a) c-Abl regulates programmed cell death and DSB repair in response to DNA damage. $c$-Abl is activated in the context of the DNA damage response. It phosphorylates $p 73^{9}$ and Yap ${ }^{12}$ and activates the p73-dependent cell death response (right panel). C-Abl also interacts with various components of DSB repair, some of which are phosphorylated by it and some of which phosphorylate c-Abl (left panel). c-Abl interacts with ATM and this interaction is likely to be involved in the activation of c-Abl. ${ }^{13,14} \mathrm{c}$-Abl associates with DNA-PK resulting in a potential reciprocal phosphorylation and interacts also with the Ku80 protein. ${ }^{15} \mathrm{c}$-Abl associates with and regulates the activity of Rad51, ${ }^{16}$ Rad52, ${ }^{17}$ WRN ${ }^{18}$ as well as BRCA1. ${ }^{19}$ The data presented herein indicate that activated c-Abl functionally downregulates DSB repair. The potential mechanism by which this downregulation occurs incorporates the various interactions of c-Abl with proteins involved in DSB repair. (b) According to our results c-Abl-mediated downregulation of DSB repair is most dominant during slow-phase DSB repair. This time-dependent pattern of repair downregulation follows the time-dependent increase in c-Abl activation in response to DNA damage and correlates with the time frame within which DSB repair is most likely to be error-prone

recruitment of DNA repair factors to the damaged DNA. c-Abl kinase activity could therefore either support effective $\gamma \mathrm{H} 2 \mathrm{AX}$ dephosphorylation or downregulate the levels of $\mathrm{H} 2 \mathrm{AX}$ phosphorylation. Notwithstanding these tentative explanations, a further and more detailed study raising these questions is required in order to uncover the exact mechanism by which c-Abl executes its function in DSB repair downregulation.

\section{Materials and Methods}

Cell culture and reagents. HeLa, MCF7, CAbl-/-, and wt MEFs were cultured in Dublecco's modified Eagle medium supplemented with $9 \%$ fetal calf serum at $37^{\circ} \mathrm{C}$ at $5 \% \mathrm{CO}_{2}$ in a humidified atmosphere. STI-571 (Novartis, Basel, Switzerland) was added at a concentration of $10 \mu \mathrm{M} 2 \mathrm{~h}$ before irradiation. A volume of DMSO equal the volume of DMSO-dissolved STI-571 was added to all control samples. Mouse monoclonal anti-phospho-H2AX antibody (Upstate-Millipore, Temecula, CA, USA, clone JBW301) was used at a concentration of 1:900 for immunofluorescence and 1:10000 for immunoblotting. Other antibodies used are as follows: anti-c-Abl (K-12), anti-phospho-Tyrosine (PY20), anti- $\beta$-tubulin, all from Santa Cruz (Santa Cruz, CA, USA), FITC-conjugated Donkey-anti-Mouse secondary antibody (Jackson laboratories, West Grove, PA, USA).

Pulsed field gel electrophoresis. For determination of DSB rejoining in a cell population, cells were seeded at a density of $\sim 35000 / \mathrm{cm}^{2}$ and $\gamma$-irradiation was performed using a Cs-137 source at a dose rate of $8 \mathrm{~Gy} / \mathrm{min}$. Cells were kept on ice before irradiation to prevent repair in time zero samples. For repair resumption, cells were returned to $37^{\circ} \mathrm{C}$ for the indicated time periods. Control samples were sham irradiated. Cells were harvested by trypsinization, collected in PBS and kept at $-20^{\circ} \mathrm{C}$ until plug preparation. For plug preparation, cells were resuspended in PBS and cell number was determined using a hemocytometer and standardized using the Bradford protein assay. Cells were then embedded in $0.7 \%$ LMP agarose (BioRad, Hercules, CA, USA) at a concentration of $6 \times 10^{6} \mathrm{cell} / \mathrm{s} / \mathrm{ml}$ and cast into $100 \mu \mathrm{l}$ plug molds ( $\sim 6 \times 10^{5}$ cells per plug). Plugs were lyzed in digestion buffer ( $0.5 \mathrm{M} \mathrm{EDTA}, \mathrm{pH} 8,1 \%$ $\mathrm{N}$-lauryl sarkosine, $1 \mathrm{mg} / \mathrm{ml}$ proteinase $\mathrm{K}$ ) at $50^{\circ} \mathrm{C}$ overnight, washed twice in TE buffer (10 mM Tris-HCL, $1 \mathrm{mM}$ EDTA, pH 8), and loaded onto a gel comb, followed by casting of the gel $(0.8 \%$ Megabase agarose (BioRad) in $0.5 \times$ TBE). DNA was separated using a BioRad CHEF DR III system at $14^{\circ} \mathrm{C}$ in $0.5 \times$ TBE with linearly increasing pulse times from $50-5000 \mathrm{~s}$ over $65 \mathrm{~h}$ at a field strength of $1.5 \mathrm{~V} / \mathrm{cm}$, followed by staining with $0.5 \mu \mathrm{g} / \mathrm{ml}$ ethidium bromide for $1 \mathrm{~h}$. Images were obtained using a digital CCD camera under UV illumination, and the fraction of DNA below the constriction zone was quantified using $\mathrm{NIH} \mathrm{ImageJ} 1.38$ software (NIH, Bethesda, MD, USA). The percent of DSBs remaining was calculated relative to the fragmentation at time zero, after correction for background fragmentation in unirradiated cells.

Neutral comet assay. For single-cell gel electrophoresis, $100 \mu \mathrm{l}$ of normal melting-point (NMP) agarose (1\% in PBS) were added to a microscope slide, coverslip covered and placed at RT overnight to allow solidification. Cells collected by trypsinization were resuspended to a density of $1 \times 10^{5} \mathrm{cell} / \mathrm{s} / \mathrm{ml}$ in PBS, and $50 \mu$ l of this suspension were mixed with $500 \mu$ l of LMP agarose, after which $75 \mu \mathrm{l}$ of the new suspension were placed on the previous agarose layer (after coverslip removal), recovered and placed at $4^{\circ} \mathrm{C}$. After solidification, another $75 \mu \mathrm{l}$ of NMP agarose were added, followed by coverslip replacement, and slides were returned to $4^{\circ} \mathrm{C}$. Subsequently, slides without coverslips were placed in chilled lysis solution (2.5 M sodium chloride, $100 \mathrm{mM}$ EDTA, pH 10, $10 \mathrm{mM}$ Tris Base, $1 \%$ sodium lauryl sarcosinate, and $1 \%$ Triton $\mathrm{X}-100$ ) at $4^{\circ} \mathrm{C}$ overnight, washed with electrophoresis buffer (TBE $\times 1$ ), subjected to electrophoresis at $20 \mathrm{~V}$ for $20 \mathrm{~min}$ at $4^{\circ} \mathrm{C}$ in the dark, and fixed in ethanol for $5 \mathrm{~min}$. To bring all cells to one plane, samples were left overnight to air-dry. Slides were stained with SYBR Green solution (SYBR Green in TE pH 7.5, Sigma-Aldrich, Rehovot, Israel). At least 100 cells were evaluated per slide using the $\times 40$ objective of an Olympus 1X70 fluorescence microscope (Olympus, Center Valley, PA, USA, distributed by Eisenberg Brothers, Ben-Gurion 
Airport, Israel). The comet tail moment was quantified using the comet scoring macro of the $\mathrm{NIH}$ image software.

Immunofluorescence microscopy. Cells were seeded at a density of 13000 cells $/ \mathrm{cm}^{2}$ on coverslips. Fixation was performed in $4 \%$ paraformaldehyde for $30 \mathrm{~min}$ followed by three washes in TBS $(10 \mathrm{mM}$ Tris $\mathrm{HCl} \mathrm{pH} 7.5,100 \mathrm{mM} \mathrm{NaCl})$, permeabilization with $0.5 \%$ Triton- $X$ for 25 min and blocking with $10 \%$ BSA in TBS at $4{ }^{\circ} \mathrm{C}$ overnight. Coverslips were incubated with anti- $\gamma \mathrm{H} 2 \mathrm{AX}$ antibody for $2 \mathrm{~h}$, washed once in TBS-T (TBS + 0.2\% Tween-20) and incubated for $1 \mathrm{~h}$ with FITC-conjugated secondary antibody, followed by nuclear staining with Hoechst-H33342 for 15 min and five washes in TBS-T. Coverslips were mounted using Fluoromount-G (Southern Biotech, Birmingham, AL, USA). Slides were analyzed with a Zeiss LSM 710 Meta confocal microscope (Getter Bio-Med Ltd., Ramat-Gan, Israel) using ZEN software. For quantitative analysis at least 50 cells were analyzed per sample.

Immunoblot analysis. For c-Abl detection, cell extracts were prepared by lysis of PBS-washed cells in RIPA buffer (1\% NP-40, 1\% sodium deoxycholate, $0.1 \%$ SDS, $150 \mathrm{mM} \mathrm{NaCl}, 50 \mathrm{mM}$ Tris- $\mathrm{HCl}$ pH 7.4, $1 \mathrm{mM}$ EDTA, $1 \mathrm{mM}$ PMSF) at $4{ }^{\circ} \mathrm{C}$ for $10 \mathrm{~min}$. The insoluble pellet was discarded, and protein concentration was determined using the Bradford protein assay (Bio-Rad). Following the addition of sample buffer, samples were boiled for $3 \mathrm{~min}$ and separated by SDS-PAGE $(8 \%$ acrylamide). For detection of $\mathrm{H} 2 \mathrm{AX}$ phosphorylation, whole cell lysates were prepared by incubation in RIPA buffer at $4^{\circ} \mathrm{C}$ for $20 \mathrm{~min}$, followed by sonication and separated by SDS-PAGE (15\% acrylamide).

In vitro kinase assay. Cells were washed twice in ice-cold PBS and cell pellets were lyzed in CSK buffer (10 mM PIPES pH 6.8, $100 \mathrm{mM} \mathrm{NaCl}, 300 \mathrm{mM}$ sucrose, $3 \mathrm{mM}$ $\mathrm{MgCl}_{2}, 1 \mathrm{mM}$ EGTA, $1 \mathrm{mM}$ PMSF, $1 \mathrm{mM} \mathrm{DTT,} \mathrm{0.5 \%} \mathrm{(v/v)} \mathrm{Triton} \mathrm{X-100} \mathrm{and} 1 \mu \mathrm{g} / \mathrm{ml}$ each of leupeptin, aprotinin, pepstatin) for $20 \mathrm{~min}$ on ice and separated by centrifugation at $4{ }^{\circ} \mathrm{C}$. For immunoprecipitation, $25 \mu \mathrm{l}$ of $50 \%$ slurry protein-A/G beads (Santa Cruz) and $2 \mu \mathrm{g}$ of anti-c-Abl antibody were added to the extract and incubated for $4 \mathrm{~h}$ at $4{ }^{\circ} \mathrm{C}$. Beads were washed five times in CSK buffer and twice in kinase buffer $(50 \mathrm{mM}$ Tris- $\mathrm{HCl}$ $\mathrm{pH} 7.5,10 \mathrm{mM} \mathrm{MgCl}_{2}, 1 \mathrm{mM}$ EGTA, $2 \mathrm{mM}$ DTT, 0.01\% Brij 35). Kinase reaction was carried out in $25 \mu$ l kinase buffer containing $1 \mu \mathrm{g}$ recombinant Abi protein as a specific substrate, $100 \mu \mathrm{M}$ ATP and $100 \mu \mathrm{g} / \mathrm{ml} \mathrm{BSA}$, at $30^{\circ} \mathrm{C}$ for $30 \mathrm{~min}$. The reaction was terminated by the addition of SDS-sample buffer and subsequent boiling. Tyrosine phosphorylation of the Abi protein was determined by WB using the PY20 antibody.

Colony-formation assay. Cells were seeded at a density of $\sim 38 \mathrm{cells} / \mathrm{cm}^{2}$. After $\gamma$-irradiation, cells were left in the incubator for 14 days, during which one medium exchange was performed. Fixation was performed with $70 \%$ isopropanol for $10 \mathrm{~min}$ followed by staining with $0.1 \%$ crystal violet. Colonies were counted and the plating efficiency (PE) was calculated according to the number of colonies in non-irradiated cells. The surviving fraction in $\gamma$-irradiated cells was calculated by dividing the number of colonies formed after irradiation by the product of the number of cells seeded and the PE.

\section{Conflict of interest}

The authors declare no conflict of interest.

Acknowledgements. This study was supported by grants from the Samuel Waxman Cancer Research Foundation and from the Israel Science Foundation (Grant no. 1040/03-18.2). STI-571 was kindly provided by Novartis Pharmaceuticals.

1. Hoeijmakers JH. Genome maintenance mechanisms for preventing cancer. Nature 2001 ; 411: 366-374.

2. Metzger L, lliakis $G$. Kinetics of DNA double-strand break repair throughout the cell-cycle as assayed by pulsed field gel-electrophoresis in cho cells. Intern J Radiat Biol 1991; 59 : $1325-1339$

3. Iliakis G, Wang H, Perrault AR, Boecker W, Rosidi B, Windhofer F et al. Mechanisms of DNA double strand break repair and chromosome aberration formation Cytogenet Genome Res 2004; 104: 14-20.

4. Shaul Y, Ben-Yehoyada M. Role of c-Abl in the DNA damage stress response. Cell Res 2005; 15: 33-35.

5. Shaul Y. c-Abl: activation and nuclear targets. Cell Death Differ 2000; 7: 10-16.

6. Kharbanda S, Ren RB, Pandey P, Shafman TD, Feller SM, Weichselbaum RR et al. Activation of the C-Abl tyrosine kinase in the stress-response to DNA-damaging agents. Nature 1995; 376: 785-788

7. Yuan ZM, Huang YY, Whang Y, Sawyers $C$, Weichselbaum R, Kharbanda S et al. Role for c-Abl tyrosine kinase in growth arrest response to DNA damage. Nature 1996; 382: 272-274.

8. Liu ZG, Baskaran R, Lea-Chou ET, Wood LD, Chen Y, Karin M et al. Three distinct signalling responses by murine fibroblasts to genotoxic stress. Nature 1996; 384: 273-276.

9. Agami R, Blandino G, Oren M, Shaul Y. Interaction of C-Abl and p73alpha and their collaboration to induce apoptosis. Nature 1999; 399: 809-813.

10. Gong JG, Costanzo A, Yang HQ, Melino G, Kaelin Jr WG, Levrero M et al. The tyrosine kinase c-Abl regulates p73 in apoptotic response to cisplatin-induced DNA damage. Nature 1999; 399: 806-809.

11. Yuan ZM, Shioya $H$, Ishiko $T$, Sun $X$, Gu J, Huang YY et al. p73 is regulated by tyrosine kinase c-Abl in the apoptotic response to DNA damage. Nature 1999; 399: 814-817.

12. Levy D, Adamovich Y, Reuven N, Shaul Y. Yap1 phosphorylation by c-Abl is a critical step in selective activation of proapoptotic genes in response to DNA damage. Mol Cell 2008; 29: $350-361$

13. Shafman T, Khanna KK, Kedar P, Spring K, Kozlov S, Yen T et al. Interaction between ATM protein and C-Abl in response to DNA damage. Nature 1997; 387: 520-523.

14. Baskaran R, Wood LD, Whitaker LL, Canman CE, Morgan SE, Xu Y et al. Ataxia telangiectasia mutant protein activates $\mathrm{C}-\mathrm{Abl}$ tyrosine kinase in response to ionizing radiation. Nature 1997; 387: 516-519.

15. Kharbanda S, Pandey P, Jin S, Inoue S, Bharti A, Yuan ZM et al. Functional interaction between DNA-PK and c-Abl in response to DNA damage. Nature 1997; 386: 732-735.

16. Yuan ZM, Huang Y, Ishiko T, Nakada S, Utsugisawa T, Kharbanda S et al. Regulation of Rad51 function by c-Abl in response to DNA damage. J Biol Chem 1998; 273: 3799-3802.

17. Kitao H, Yuan ZM. Regulation of ionizing radiation-induced Rad52 nuclear foci formation by c-Abl-mediated phosphorylation. J Biol Chem 2002; 277: 48944-48948.

18. Cheng WH, von Kobbe C, Opresko PL, Fields KM, Ren J, Kufe D et al. Werner syndrome protein phosphorylation by abl tyrosine kinase regulates its activity and distribution. $\mathrm{Mol}$ Cell Biol 2003; 23: 6385-6395.

19. Foray N, Marot D, Randrianarison V, Venezia ND, Picard D, Perricaudet M et al. Constitutive association of BRCA1 and c-Abl and its ATM-dependent disruption after irradiation. Mol Cell Biol 2002; 22: 4020-4032.

20. Brasher BB, Van Etten RA. c-Abl has high intrinsic tyrosine kinase activity that is stimulated by mutation of the Src homology 3 domain and by autophosphorylation at two distinct regulatory tyrosines. J Biol Chem 2000; 275: 35631-35637.

21. Tanis KQ, Veach D, Duewel HS, Bornmann WG, Koleske AJ. Two distinct phosphorylation pathways have additive effects on Abl family kinase activation. Mol Cell Biol 2003; 23: 3884-3896.

22. Collins AR. The comet assay for DNA damage and repair: principles, applications, and limitations. Mol Biotechnol 2004; 26: 249-261.

23. Olive PL, Banath JP. The comet assay: a method to measure DNA damage in individual cells. Nat Protoc 2006; 1: 23-29.

24. Herschleb J, Ananiev G, Schwartz DC. Pulsed-field gel electrophoresis. Nat Protoc 2007; 2: $677-684$.

25. Rothkamm K, Kruger I, Thompson LH, Lobrich M. Pathways of DNA double-strand break repair during the mammalian cell cycle. Mol Cell Biol 2003; 23: 5706-5715.

26. Stucki M, Jackson SP. gammaH2AX and MDC1: anchoring the DNA-damage-response machinery to broken chromosomes. DNA Repair (Amst) 2006; 5: 534-543.

27. Celeste A, Difilippantonio S, Difilippantonio MJ, Fernandez-Capetillo O, Pilch DR, Sedelnikova $\mathrm{OA}$ et al. H2AX haploinsufficiency modifies genomic stability and tumor susceptibility. Cell 2003; 114: 371-383.

28. Yuan ZM, Huang Y, Ishiko T, Kharbanda S, Weichselbaum R, Kufe D. Regulation of DNA damage-induced apoptosis by the c-Abl tyrosine kinase. Proc Natl Acad Sci USA 1997; 94: $1437-1440$

29. Brown JM, Evans JW, Kovacs MS. Mechanism of chromosome exchange formation in human fibroblasts: insights from 'chromosome painting'. Environ Mol Mutagen 1993; 22: 218-224.

30. Lobrich M, Rydberg B, Cooper PK. Repair of X-ray-induced DNA double-strand breaks in specific Not I restriction fragments in human fibroblasts: joining of correct and incorrect ends. Proc Natl Acad Sci USA 1995; 92: 12050-12054.

31. Wang JY. Regulation of cell death by the Abl tyrosine kinase. Oncogene 2000; 19 : 5643-5650.

32. Gonfloni S, Di Tella L, Caldarola S, Cannata SM, Klinger FG, Di Bartolomeo C et al. Inhibition of the c-Abl-TAp63 pathway protects mouse oocytes from chemotherapy-induced death. Nat Med 2009; 15: 1179-1185.

33. Lin YL, Sengupta S, Gurdziel K, Bell GW, Jacks T, Flores ER. p63 and p73 transcriptionally regulate genes involved in DNA repair. PLoS Genet 2009; 5: e1000680.

34. Sengupta S, Harris CC. p53: traffic cop at the crossroads of DNA repair and recombination. Nat Rev Mol Cell Biol 2005; 6: 44-55.

35. Fanta S, Sonnenberg M, Skorta I, Duyster J, Miething C, Aulitzky WE et al. Pharmacological inhibition of c-Abl compromises genetic stability and DNA repair in Bcr-Abl-negative cells. Oncogene 2008; 27: 4380-4384.

(c)

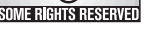
licensed under a Creative Commons Attribution-Noncommercial-No
Derivative Works 3.0 License. To view a copy of this license, visit http:// licensed under a Creative Commons Attribution-Noncommercial-No
Derivative Works 3.0 License. To view a copy of this license, visit http:// creativecommons.org/licenses/by-nc-nd/3.0/
Cell Death and Disease is an open-access journal published by Nature Publishing Group. This article is 